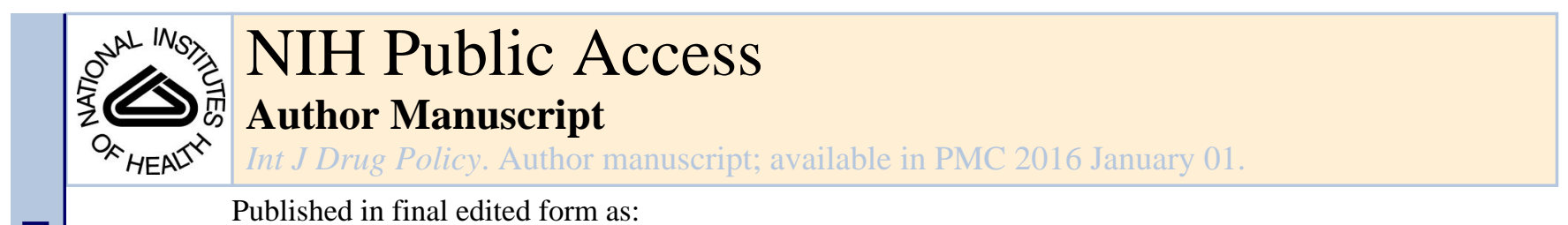

Published in final edited form as:

Int J Drug Policy. 2015 January ; 26(1): 59-66. doi:10.1016/j.drugpo.2014.07.010.

\title{
Prevalence and Correlates of Nonmedical Prescription Opioid Use Among a Cohort of Sex Workers in Vancouver, Canada
}

\author{
Elena Argento ${ }^{a}$, Jill Chettiar ${ }^{\mathrm{a}, \mathrm{b}}$, Paul Nguyen $^{\mathrm{a}}$, Julio Montaner ${ }^{\mathrm{a}, \mathrm{c}}$, and Kate Shannon ${ }^{\mathrm{a}, \mathrm{b}, \mathrm{c}}$ \\ aBritish Columbia Centre for Excellence in HIV/AIDS, St. Paul's Hospital, 608-1081 Burrard \\ Street, Vancouver, BC, CANADA, V6Z 1 Y6 \\ bSchool of Population and Public Health, University of British Columbia, 5804 Fairview Avenue, \\ Vancouver, BC, CANADA, V6T 1 Z3 \\ 'Department of Medicine, University of British Columbia, St. Paul's Hospital, 608-1081 Burrard \\ Street, Vancouver, BC, CANADA, V6Z 1 Y6
}

\begin{abstract}
Background-The nonmedical use of prescription opioids (POs) is a major public health concern, causing extensive morbidity and mortality in North America. Canada has the second highest consumption rate of POs globally and data indicate nonmedical PO use (NPOU) is growing among key populations and increasingly available in street-level drug markets. Despite accumulating evidence documenting the rise of NPOU, few studies have systematically examined NPOU in Canada among key vulnerable populations, such as sex workers. This study prospectively evaluated the prevalence and correlates of NPOU within a Vancouver cohort of sex workers over three-years follow-up.

Methods-Data were drawn from an open prospective cohort, AESHA (An Evaluation of Sex Workers Health Access) in Metro Vancouver, Canada (2010-2013). Women were recruited through outreach from outdoor street locations and indoor venues. Bivariate and multivariable logistic regression using Generalized Estimating Equations (GEE) were used to examine social and structural correlates of NPOU over 36 months.
\end{abstract}

Results-Of the 692 sex workers at baseline, close to one-fifth ( $n=130,18.8 \%)$ reported NPOU (injection or non-injection) in the last six months. In multivariable GEE analyses, factors independently correlated with recent NPOU were: exchanging sex while high (AOR 3.26, 95\%CI 2.29-4.64), police harassment/arrest (AOR 1.83, 95\% CI 1.43-2.35), intimate partner injects drugs (AOR 1.66, 95\% CI 1.11-2.49), and recent physical/sexual intimate partner violence (AOR 1.65, 95\%CI 1.21-2.24).

(c) 2014 Elsevier B.V. All rights reserved.

Send correspondence to: Kate Shannon, PhD, MPH, Associate Professor, Department of Medicine, University of British Columbia, Director, Gender and Sexual Health Initiative, B.C. Centre for Excellence in HIV/AIDS, St. Paul's Hospital, 608-1081 Burrard Street, Vancouver, B.C., V6Z 1Y6, Canada, Tel: (604) 804-9459, Fax: (604) 806-9044, gshi@cfenet.ubc.ca.

Conflicts of Interest: The authors declare no conflict of interest.

Publisher's Disclaimer: This is a PDF file of an unedited manuscript that has been accepted for publication. As a service to our customers we are providing this early version of the manuscript. The manuscript will undergo copyediting, typesetting, and review of the resulting proof before it is published in its final citable form. Please note that during the production process errors may be discovered which could affect the content, and all legal disclaimers that apply to the journal pertain. 
Conclusion-Our results demonstrate that nearly one-fifth of sex workers in Metro Vancouver report NPOU. Factors independently statistically associated with NPOU included exchanging sex while high, police harassment/arrest, a drug injecting intimate partner and recent physical/sexual intimate partner violence. The high prevalence of NPOU use among sex workers underscores the need for further prevention and management strategies tailored to this key population. The correlates of NPOU uncovered here suggest that structural interventions may be further implemented to ameliorate this growing concern.

\section{Keywords}

Prescription opioids; Sex workers; Drug use; Substance use; Canada

\section{INTRODUCTION}

The nonmedical use of prescription opioids (POs) has emerged as a major public health concern, especially in North America where it has reached epidemic proportions, causing extensive morbidity and mortality (Dhalla et al., 2009; Fischer \& Argento, 2012; Manchikanti, Boswell, \& Hirsch, 2013). POs, pharmaceutical analgesic drugs (such as oxycodone and hydrocodone) designed for the treatment of moderate to severe chronic pain, are the most commonly misused class of prescription drugs (Fischer \& Argento, 2012; Substance Abuse and Mental Health Service Administration, 2010). In the United States, PO-related deaths are now the second leading cause of unintentional death, after motor vehicle accidents and overdoses from POs cause more deaths than heroin and cocaine combined (Centers for Disease Control and Prevention, 2012; Volkow \& McLellan, 2011). Emergency room visits involving PO misuse with oxycodone and hydrocodone increased dramatically by $242.2 \%$ and $124.5 \%$, respectively, between 2004 and 2009 (Substance Abuse and Mental Health Service Administration, 2010).

Canada has the second highest PO consumption rate in the world (International Narcotics Control Board, 2012). It has been estimated that the harms from PO misuse in Canada now constitute the third highest overall substance use burden (after alcohol and tobacco) and that up to 1.25 million Canadians use POs for nonmedical purposes (Fischer \& Rehm, 2011). There has been significant variation in the estimated prevalence of PO misuse among the general adult population in Canada; an updated 2010 survey in Ontario estimated the prevalence of nonmedical PO use (NPOU) to be as high as 7.7\% (95\% CI: 6.3\% to 9.2\%), while the 2008/2009 Centre for Addiction and Mental Health (CAMH) Monitor survey found NPOU to be much lower at $2.0 \%$ (95\% CI: $1.2 \%$ to 2.8\%) (Shield, Ialomiteanu, Fischer, \& Rehm, 2013). Canada has seen PO-related deaths rise substantially; over a fiveyear period (1994-1999) oxycodone-related mortality in Ontario rose four fold $(p<0.01)$ (Dhalla, Mamdani, Gomes, \& Juurlink, 2011).

A growing body of literature documents trends in increasingly problematic PO use and street-level availability in Canada: data indicate that rates of NPOU are rising in general adult and student populations (Boak, Hamilton, Adlaf, \& Mann, 2013; Health Canada, 2013) and NPOU is emergent among key marginalized populations, including street-drug users (Popova, Patra, Mohapatra, Fischer, \& Rehm, 2009), First Nations/Aboriginal people (Dell 
et al., 2012; Katt et al., 2012), and correctional populations (Johnson, MacDonald, Cheverie, Myrick, \& Fischer, 2012). Local Vancouver studies of youth and adults who use drugs have seen a marked rise in the availability of POs, particularly oxycodone and hydrocodone, in street-level drug markets between 2006 and 2010, despite the high and stable availability of other illicit drugs (Nosyk et al., 2012), and injection and non-injection PO use has surpassed heroin use among some drug-using populations in Canada (Fischer et al., 2006; Leclerc, Morissette, \& Roy, 2010).

Given the overlap between street-based drug use and sex work scenes, female sex workers represent a particularly vulnerable population to drug use and yet data on NPOU among sex workers are rare. A study among drug involved female sex workers (sex workers) in Miami found that $12.2 \%$ of the sample used at least one PO in the past 90 days without having a legitimate prescription and that those who were recently physically abused/victimized or currently used cocaine or heroin were more likely to abuse POs (Surratt, Inciardi, \& Kurtz, 2006). Sex workers already suffer a high burden of poverty, disease, and violent victimization, which may be exacerbated by adverse health consequences and correlates of NPOU. Women in general represent a large and growing fraction of the NPOU population (Cicero, Lynskey, Todorov, Inciardi, \& Surratt, 2008; Green, Grimes Serrano, Licari, Budman, \& Butler, 2009; Tetrault et al., 2008). Emergency room visits related to NPOU among women in the US doubled between 2004 and 2010 and the percentage increase in overdose deaths since 1999 was significantly greater among women (151\%) than men (85\%) (Centers for Disease Control and Prevention, 2013). In Canada, First Nations communities in northwestern Ontario are experiencing alarming increases in the rates of NPOU among pregnant women; the incidence of oxycodone abuse during pregnancy rose from $8.4 \%$ in 2009 to $17.2 \%$ in 2010 (Kelly et al., 2011). Research indicates that NPOU is highly correlated with mental health comorbidities (Amari, Rehm, Goldner, \& Fischer, 2011; Katz, El-Gabalawy, Keyes, Martins, \& Sareen, 2013; Martin, Woodall, \& McLellan, 2006; Sproule \& Li, 2009), which tend to be higher among females than among men (Cicero et al., 2008; Wu, Woody, Yang, \& Blazer, 2011).

Despite accumulating evidence of increasing NPOU and related harms, few studies have systematically examined the prevalence and correlates of PO use in subpopulations, particularly among marginalized groups such as sex workers. Therefore, the objective of this study was to provide a prospective analysis of the prevalence and correlates of NPOU among a cohort of female sex workers in Vancouver, Canada over three years of follow-up.

\section{METHODS}

\section{Study Design and Sample}

Data for this study were drawn from an ongoing open prospective cohort of female sex workers, AESHA (An Evaluation of Sex Workers Health Access) that initiated recruitment in January 2010. Eligibility criteria at baseline included being female (trans*-inclusive) older than 14 years of age, having exchanged sex for money within the last 30 days (at baseline and at follow-up), and providing written informed consent. Eligibility for the current prospective analyses included completing at least one baseline and one follow-up visit between January 2010 and February 2013. 
In the context of hard-to-reach populations, sex workers were recruited through community mapping and time-location sampling. As executed previously, outdoor and indoor venues were identified through participatory mapping strategies conducted with current/former sex workers (and continuously updated by the outreach team) to identify sex work locations (Shannon et al., 2007). Using systematic time-location sampling, considered a useful method of recruitment for mobile/hidden populations (Stueve, Duran, Doval, \& Blome, 2001), sex workers were recruited through day and late night outreach to both outdoor (i.e. streets, alleys) and indoor sex work venues (i.e. massage parlors, micro-brothels, and in-call locations) across Metro Vancouver. In addition, online recruitment was used to reach sex workers working through online solicitation spaces.

At enrolment and bi-annually, participants complete an interviewer-administered questionnaire by a trained interviewer and HIV/STI/HCV serology testing by a project nurse. The main interview questionnaire elicits responses related to socio-demographics (e.g. sexual identity, ethnicity, housing), the sex industry (e.g. work environment, solicitation, social cohesion, access to services, violence/safety, incarceration), clients (e.g. number/type of clients, types of services, condom use), intimate partners (e.g. sexual history, cohabitation, financial support), trauma and violence (e.g. lifetime and childhood trauma, exposure to intimate partner and workplace violence), and drug use patterns (injection and non-injection). In addition, a clinical questionnaire is administered relating to overall physical, mental and emotional health, sexual and reproductive health, and HIV testing and treatment experiences. Sex workers have the option to visit one of two study offices or complete the questionnaire and clinical component at a safe location identified by them, including work or home locations. All participants receive an honorarium of \$40CAD at each bi-annual visit for their time, expertise and travel.

Ethics Statement-The AESHA study holds ethical approval through Providence Health Care/University of British Columbia Research Ethics Board and has a community advisory board of over 15 agencies.

\section{Study Variables}

Nonmedical Prescription Opioid Use Outcome-Our dependent variable of interest was recent NPOU, defined as responding 'yes' to any nonmedical injection or nonmedical non-injection PO use in the last six months (i.e. responded 'yes' to street methadone, dilaudid, morphine, oxycontin, or T3s/T4s). Probing questions were asked to determine whether the POs were prescribed to the participant or not. If the POs were either diverted by the participant (i.e. purchased from an acquaintance or on the street) or prescribed to the participant being interviewed, but not taken as prescribed (i.e. either injected or taken more frequently/in greater quantity than as prescribed) then they were considered to be used for nonmedical purposes. The NPOU variable did not include any medical use of POs.

Individual and Historical Factors-Fixed variables considered at baseline included demographic variables such as: age (continuous), sexual minority (lesbian, gay, bisexual, transgender, transsexual, or two-spirited), being of Aboriginal/Indigenous ancestry (inclusive of First Nations, Metis, and Inuit), and being a migrant/new immigrant worker 
(versus Canadian born). Historical exposure to childhood physical and/or sexual abuse $(<18$ years of age) was also included. Individual variables including education level and injection and non-injection drug use were collected at baseline and time-updated based on the last six months at each follow-up visit.

Socio-structural Factors-Social and structural variables including primary place of soliciting and servicing clients, exchanging sex for drugs, exchanging sex while high, physical or sexual violence from clients and intimate partners, police harassment (without arrest), police arrest, and intimate partner-level data (e.g. inconsistent condom use for vaginal/anal sex, sourcing drugs from intimate partners, and injection or non-injection drug use by intimate partners) were collected at baseline and time-updated based on the last six months at each follow-up visit.

\section{Statistical Analyses}

Socio-demographic variables (age, ethnicity, sexual minority, migrant status) were considered fixed variables. All other variables were considered time varying, and were updated to reflect their occurrence within the last six months. Since analyses of factors potentially associated with prevalence of NPOU during follow-up included time-updated serial measures for each participant, bivariable and multivariable generalized estimating equations (GEE) with a logit link function for binary outcomes were used to determine which factors were independently associated with NPOU in the last 6 months. Therefore, data from every follow-up visit was considered in this analysis. For example, an individual participant may have reported NPOU on and off during follow-up and this approach serves to examine variables that correlated with times of NPOU versus times when NPOU is not reported. To adjust the standard error and account for correlations arising from the five repeated measurements on the same participant over the three-year follow-up period, an exchangeable correlation matrix was applied. GEE accounts for missing data using the all available pairs method, which uses data from non-missing pairs into the estimators of the correlation matrix. Variables significantly correlated with PO use at the $p<0.05$ level in bivariate analyses were subsequently fitted into a multivariable GEE model to adjust for potential confounding. Quasi-likelihood Information Criteria (QIC) selection was used to build the final multivariable model, which has been used successfully in past research by our group (Deering et al., 2013). Two-sided p-values and unadjusted and adjusted odds ratios (OR and AOR) with 95\% confidence intervals (95\% CI) are reported. All statistical analyses were performed using SAS software package version 9.3 (SAS Institute, Cary, NC, USA).

\section{RESULTS}

\section{Descriptive Results}

A total cohort of 692 sex workers completed a baseline and at least one follow-up visit between January 2010 and February 2013. Baseline individual and socio-structural characteristics of participants who reported recent NPOU compared to those who did not are displayed in Table 1. Overall, close to one-fifth $(n=130,18.8 \%)$ reported NPOU (injection or non-injection) in the last six months at baseline, with $19.2 \%$ events of NPOU over the follow-up period. Within the study sample, $25.6 \%$ self-identified as a sexual minority 
(lesbian, bisexual, transgender, two spirited) and $36.3 \%$ as being of Aboriginal ancestry. A full $73.4 \%$ were born in Canada, and $52.2 \%$ had an educational level of high school or greater. Physical or sexual childhood abuse (before age 18 years) was reported by $71.2 \%$ of participants. Regarding drug use, $69.4 \%$ and $40.0 \%$ reported non-injection and injection illicit drug use (excluding cannabis) at baseline, respectively, in the last six months.

Additionally $61.4 \%$ reported exchanging sex while high, and this was statistically significantly higher among those with recent NPOU $(90.0 \%)$ than those without $(54.8 \%)$ $(p<0.001)$. Police harassment and/or arrest in the last six months (including, detained against will/followed/moved by police, confiscation of property, condoms or drug use paraphernalia without arrest, physical abuse without arrest, coerced into providing sexual favours) was reported by $40 \%$ of participants, and this was more prevalent among those with recent NPOU $(60.0 \%)$ than those without $(35.4 \%)(p<0.001)$. Recent physical/sexual violence by clients was reported by $23.4 \%$ of participants and $21.2 \%$ reported recent physical/sexual violence by intimate partners, which were both higher among those who reported recent NPOU than those who did not $(p<0.001)$.

\section{Bivariate and Multivariable GEE Analyses}

Bivariate and adjusted odds ratios for independent correlates with recent NPOU are displayed in Table 2 . In bivariate GEE analyses, factors positively correlated with recent NPOU at $p<0.05$ included: non-injection drug use (OR 23.95, 95\%CI 12.18-47.10); born in Canada (OR 9.31, 95\%CI 4.14-20.98), injection drug use (OR 5.92, 95\%CI 4.25-8.25); exchanged sex while high (OR 3.74, 95\%CI 2.76-5.06); childhood abuse (OR 2.94, 95\%CI 1.91-4.52); exchanged sex for drugs (OR 2.56, 95\%CI 1.97-3.32); police harassment/arrest (OR 2.38, 95\%CI 1.89-3.01); injection drug use by intimate partner (OR 2.27, 95\% CI 1.55-3.31); physical and/or sexual violence by intimate partner (OR 2.12, 95\%CI 1.57-2.86); physical and/or sexual violence by client (OR 1.82, 95\%CI 1.41-2.35); non-injection drug use by intimate partner (OR 1.76, 95\% CI 1.36-2.28); sourced drugs from intimate partner (OR 1.66, 95\%CI 1.21-2.28); and sexual minority (OR 1.65, 95\%CI 1.19-2.28). Soliciting clients from indoor establishments (vs. street/public spaces) was correlated with a 74\% reduced odds of recent NPOU (OR 0.26, 95\%CI 0.15-0.44).

In the final multivariable GEE model, exchanging sex while high (AOR 3.26, 95\% CI 2.29-4.64), police harassment/arrest (AOR 1.83, 95\% CI 1.43-2.35), injection drug use by an intimate partner (AOR 1.66, 95\%CI 1.11-2.49), and recent physical and/or sexual violence from an intimate partner (AOR 1.65, 95\% CI 1.21-2.24) were independently correlated with NPOU in the last six months.

\section{DISCUSSION}

Our results demonstrate that nearly one-fifth of sex workers in Metro Vancouver report NPOU. Factors independently statistically associated with NPOU in this setting included exchanging sex while high, police harassment/arrest, having a drug injecting intimate partner and recent physical/sexual intimate partner violence. This study provides some of the first empirical evidence documenting the prevalence and characteristics of sex workers who use nonmedical POs. To our knowledge, this is the first study to provide a prospective 
analysis of the prevalence and correlates of recent NPOU among a cohort of sex workers in Canada; and among the first in higher income settings globally.

The results of this study correspond with a growing body of research that establishes links between PO use and experiences of victimization or abuse (Buttram, Kurtz, Surratt, \& LeviMinzi, 2013; Stene, Dyb, Tverdal, Jacobsen, \& Schei, 2012; Surratt et al., 2006). In our current study, recent physical and/or sexual violence by an intimate partner was independently correlated with NPOU in the last six months (AOR 1.65, 95\% CI 1.21-2.24). Globally, sex workers continue to face disproportionately high levels of violence (Argento et al., in press; Deering et al., 2014; Shannon \& Csete, 2010), and unequal power dynamics within intimate partner relationships play a key role in shaping health risks (Dunkle et al., 2006; Jewkes, Dunkle, Nduna, \& Shai, 2010; Shannon et al., 2012; Stockman, Lucea, \& Campbell, 2013). For example, among a cohort of drug-using women in the US, results indicated bi-directional temporal relationships between sexual and physical intimate partner violence and risk of HIV/STI transmission (El-Bassel, Gilbert, Wu, Go, \& Hill, 2005). A study involving a sample of adolescent ER patients, of which $8.7 \%$ reported past year NPOU, found dating violence was positively correlated with NPOU (OR 1.47, 95\% 1.00 -2.17) (Whiteside et al., 2013). Of note, while NPOU in our study was significantly higher among sex workers working in street-based settings, $6.5 \%$ of sex workers working indoors (both informal venues, such as bars, hotels, saunas; and formal sex work/'in-call' establishments) reported NPOU, reflecting the diversity of populations using POs nonmedically and suggesting that other factors such as partner violence may play an important role in NPOU.

There are complex and synergistic effects between substance use, violence and HIV risk among sex workers, including the associations between high rates of childhood abuse among sex workers (Rio Navarro, Cohen, Rocillo Arechaga, Zuniga, \& Act, 2012; Stolz et al., 2007), and the subsequent likelihood of experiences of physical or sexual violence and injection drug use later in life (Kerr et al., 2009; Strathdee et al., 1997; Ulibarri et al., 2010). In our study, an alarming $71 \%$ reported childhood abuse (before age 18 years), which was higher among those with recent NPOU (87\%) than those without (68\%), and in bivariate analyses the odds of recent NPOU were significantly increased by recent client violence (OR 1.82, 95\% CI 1.41-2.35) and intimate partner violence (OR 2.12, 95\% CI 1.57-2.86). These findings support existing literature documenting the normalization of violence and victimization among criminalized, isolated and street-involved environments (Bourgois, Prince, \& Moss, 2004; Decker, Pearson, Illangasekare, Clark, \& Sherman, 2013; Rhodes, Simic, Baros, Platt, \& Zikic, 2008; Shannon et al., 2008), and the role of physical and sexual violence from intimate partners in elevating HIV risk for sex workers (Argento et al., in press). Integrated violence and HIV prevention/intervention strategies tailored to this key population are needed, yet the extent to which screening for intimate partner violence improves health outcomes for women remains unclear (Hegarty et al., 2013; Macmillan et al., 2009) and implementation of effective screening for violence is a key challenge in highrisk populations (Ramachandran, Covarrubias, Watson, \& Decker, 2013). Stigma remains as a primary barrier to accessing violence prevention and health care services for sex workers; therefore, health care facilities and programs need to work in partnership with sex workers to reduce stigma and discrimination and improve access to health (Lazarus et al., 2012). 
Previous research has shown that HIV risk among sex workers who use drugs is particularly shaped by the role of structural violence and gendered power inequities where drug sharing with intimate, non-paying partners occurs (Bourgois et al., 2004; Shannon et al., 2008). Having a sexual partner who injects drugs has been linked to transitioning to injection (Firestone \& Fischer, 2008; Sherman, Smith, Laney, \& Strathdee, 2002; Surratt, Kurtz, \& Cicero, 2011). Further, our findings indicate that having an intimate partner who injects drugs significantly increases the odds of NPOU (AOR 1.66, 95\%CI 1.11-2.49).

The misuse of POs has been associated with a diversity of other injection and non-injection substance abuse (Buttram et al., 2013; Lankenau et al., 2012; Pergolizzi et al., 2012; Wu et al., 2011). In a US study among 515 men who have sex with men (MSM), NPOU was significantly associated with recent injection drug use (AOR 2.20, 95\% CI 1.12-4.31,p<0.05) and substance dependence (AOR 2.15, 95\% CI 1.25-3.69, $p<0.05$ ) (Buttram et al., 2013). The risk of HIV/STI among injection PO users is an emerging concern (McCabe, Cranford, Boyd, \& Teter, 2007; Surratt et al., 2011; Young, Havens, \& Leukefeld, 2010). Our findings demonstrate that of those who recently injected drugs, $79 \%$ also reported recent NPOU compared to $31 \%$ who did not $(p<0.001)$.

As a result of the increased presence and availability of POs in street drug markets, the drug use profile of street-drug users who also use POs has become increasingly diversified, posing considerable adverse health risks (Firestone \& Fischer, 2008). HIV and HCV rates of up to $20 \%$ and $66 \%$ respectively have been found among street-drug users who use also POs (Bruneau, Roy, Arruda, Zang, \& Jutras-Aswad, 2012; Fischer et al., 2005).

The structural context plays an important role in shaping the risk environment among sex workers who use drugs (Blankenship \& Koester, 2002; Shannon et al., 2008). Increasing evidence demonstrates that criminalized sex work environments and policing subvert harm reduction initiatives (Krüsi et al., 2012; Shannon et al., 2008). Policing practices in Vancouver have been shown to exacerbate drug and sexual-related harms, violence, and other HIV-related vulnerabilities among street-involved drug users (Werb et al., 2008) and sex workers who use drugs (Shannon et al., 2009; Shannon et al., 2008). Current injection drug use among sex workers has been shown to be independently associated with police sexual coercion (AOR 2.09, 95\%CI 1.45-3.02) (Odinokova, Rusakova, Urada, Silverman, \& Raj, 2013); potentially through increased visibility and/or police targeting of this highly vulnerable sub-population. Our study also indicates that police harassment is correlated with drug use: sex workers who recently experienced harassment by police were significantly more likely to report recent NPOU.

The criminalized environment and policing strategies in Vancouver continue to undermine the health and safety of sex workers and other street-involved populations (Goldenberg et al., 2014; Shannon et al., 2009; Small, Kerr, Charette, Schechter, \& Spittal, 2006; Werb et al., 2008). Enforcement-based policies have been shown to negatively impact sex workers' ability to negotiate safer sex transactions with clients, including condom use and reporting violence to police (Rhodes et al., 2008; Shannon \& Csete, 2010). A recent qualitative study among sex workers in Vancouver provides further insight into the lack of evidence-based policies operating in Canada that have serious implications for the health and safety of sex 
workers, even with the implementation of a new enforcement policy that criminalizes and targets sex buyers rather than sex workers (Krüsi et al., 2014). In December 2013, the Supreme Court of Canada unanimously struck down three of Canada's core prostitution laws on the basis they were violating sex workers' constitutional rights (Supreme Court of Canada, 2013). However, new amendments to sex work legislation in Canada proposed by the federal government (in June 2014) threaten to reproduce the risks and harms created by criminalizing sex work, severely limiting sex workers' ability to work together and protect themselves from occupational hazards; legislative provisions include criminalizing the purchase of sexual services, communicating for the purpose of selling sex, receiving material benefit from sex work, and advertising sexual services (Minister of Justice and Attorney General of Canada, 2014).

Targeted interventions for NPOU in Canada continue to be constrained by a highly fragmented data and monitoring system for NPOU and PO-related harms (Fischer \& Argento, 2012; Fischer, Gooch, Goldman, Kurdyak, \& Rehm, 2014). POs obtained for nonmedical purposes are sourced through various diversion routes in Canada, the most common being via "double-doctoring" (i.e. fraudulently obtaining prescriptions from different physicians) and through street-drug markets (Fischer et al., 2009; Haydon, Fischer, Monga, \& Adlaf, 2005; Sproule \& Li, 2009). While Canada has developed and implemented prescription-monitoring programs (PMPs) in most provinces (designed to reduce the misuse of prescription drugs), they vary significantly and their impacts on reducing harms from NPOU have yet to be assessed (Fischer \& Argento, 2012; Furlan et al., 2014). The federal government has, in the past, developed tools for guiding health practitioners and pharmacists on how to recognize prescription shoppers and minimize abuse (Health Canada, 2006), but Canada still lags behind in terms of key basic prevention measures, such as safe pharmaceutical drug storage and drug return/recycling programs (Doyle, 2010; Fischer \& Argento, 2012).

Unlike the US and Australia, a national strategy for NPOU has been absent in Canada until only recently. In March 2013, a new national prescription drug strategy, "First Do No Harm: Responding to Canada's Prescription Drug Crisis," was presented by the Canadian Centre on Substance Use (National Advisory Committee on Prescription Drug Misuse, 2013). The new strategy aims to implement and address five streams of action: Prevention, Education, Treatment, Monitoring and Surveillance, and Enforcement; however, its role in government policy-making and impact remain unclear (Fischer et al., 2014). Other recent policy interventions aimed at NPOU include the introduction of Ontario's electronic PMP and delisting of OxyContin (controlled-release oxycodone) from the Ontario Drug Benefit formulary in 2012 (Ontario Ministry of Health and Long-Term Care, 2012), which was then followed by the federal government's approval of licensing generic oxycodone products (Health Canada, 2012).

Until a national monitoring system for NPOU is effectively implemented, data/knowledge gaps remain, as does the implementation of successful interventions for NPOU-related harms, particularly among marginalized populations. 


\section{Limitations}

There are a number of strengths and limitations to consider in the interpretation of this study. Strengths of this study include the prospective design and GEE analyses, which increased the number of observations allowing average estimates of the correlates of NPOU over a three-year period to be determined. Several variables examined in this study were sensitive (i.e. childhood abuse, drug use, partner violence), which may have resulted in under-reporting or respondent-driven reporting biases by our participants. However, the interviewer-administered questionnaires were conducted in safe and comfortable spaces by experienced interviewers (including current/former sex workers), with strong community rapport, and there is no reason to believe there would be differences in reporting between PO and non-PO users. Although our findings may not be fully generalizable to other sex worker populations/settings, our study population included sex workers from a wide-ranging representation of sex work environments. The mapping of working areas and time-location sampling likely helped to ensure a representative sample and to minimize selection bias; however more higher-income earning and independent sex workers (e.g. escorts; online) are likely underrepresented.

\section{CONCLUSION}

Our results demonstrate that nearly one-fifth of sex workers in Metro Vancouver report recent NPOU. Factors independently associated with NPOU in this setting included exchanging sex while high, police harassment/arrest, a drug injecting intimate partner and recent physical/sexual intimate partner violence. The high prevalence of NPOU among sex workers underscores the need for further prevention and management strategies tailored to this key population. The correlates of NPOU uncovered here suggest that structural interventions may be further implemented to ameliorate this growing concern.

\section{Acknowledgments}

We thank all those who contributed their time and expertise to this project, including participants, partner agencies and the AESHA Community Advisory Board. We wish to acknowledge Peter Vann, Gina Willis, Sabina Dobrer, Ofer Amram, Jennifer Morris, Brittney Udall, Rachel Nicoletti, Julia Homer, Emily Leake, Chrissy Taylor, Vivian Liu, Jane Li, Tina Ok, Rhiannon Hughes, Eva Breternitz and Sylvia Machat for their research and administrative support. This research was supported by operating grants from the US National Institutes of Health (R01DA028648) and Canadian Institutes of Health Research (HHP-98835).

KS is supported by US National Institutes of Health (R01DA028648).

\section{References}

Amari E, Rehm J, Goldner E, Fischer B. Nonmedical prescription opioid use and mental health and pain comorbidities: A narrative review. Canadian Journal of Psychiatry. 2011; 56(8):495-502.

Argento E, Muldoon K, Duff P, Simo A, Deering K, Shannon K. High prevalence and partner correlates of physical and sexual violence by intimate partners among street and off-street sex workers. PLOS ONE. 2014 in Press.

Blankenship K, Koester S. Criminal law, policing policy, and HIV risk in female street sex workers and injection drug users. The Journal of Law, Medicine \& Ethics. 2002; 30(4):548-559.

Boak, A.; Hamilton, H.; Adlaf, E.; Mann, R. Drug Use Among Ontario Students 1977-2013: Detailed OSDUHS Findings (CAMH Research Document Series Report No: 36). Toronto, ON: 2013. 
Retrieved from http://www.camh.ca/en/research/news_and_publications/ontario-student-drug-useand-health-survey/Pages/default.aspx on April 21, 2014

Bourgois P, Prince B, Moss A. The everyday violence of hepatitis C among young women who inject drugs in San Francisco. Human Organization. 2004; 63(3):253-264. [PubMed: 16685288]

Bruneau J, Roy E, Arruda N, Zang G, Jutras-Aswad D. The rising prevalence of prescription opioid injection and its association with hepatitis $\mathrm{C}$ incidence among street-drug users. Addiction. 2012; 107(7):1318-1327.10.1111/j.1360-0443.2012.03803.x [PubMed: 22248184]

Buttram ME, Kurtz SP, Surratt HL, Levi-Minzi Ma. Health and social problems associated With prescription opioid misuse among a diverse sample of substance-using MSM. Substance Use and Misuse. 2013:1-8.10.3109/10826084.2013.828754 [PubMed: 23153043]

Centers for Disease Control and Prevention. CDC Grand Rounds: Prescription Drug Overdoses - a US Epidemic. 2012. p. 10-13.Retrieved from http://www.cdc.gov/mmwr/preview/mmwrhtml/ mm6101a3.htm on April 20, 2014

Centers for Disease Control and Prevention. CDC Vital Signs: Overdoses of Prescription Opioid Pain Relievers and Other Drugs Among Women - United States, 1999-2010. 2013:537-542.

Cicero TJ, Lynskey M, Todorov A, Inciardi JA, Surratt HL. Co-morbid pain and psychopathology in males and females admitted to treatment for opioid analgesic abuse. PAIN. 2008; 139(1):127-135. http://dx.doi.org/10.1016/j.pain.2008.03.021. [PubMed: 18455314]

Decker MR, Pearson E, Illangasekare SL, Clark E, Sherman SG. Violence against women in sex work and HIV risk implications differ qualitatively by perpetrator. BMC Public Health. 2013; 13(1): 876.10.1186/1471-2458-13-876 [PubMed: 24060235]

Deering K, Amin A, Shoveller J, Nesbitt A, Garcia-Moreno C, Duff P, Shannon K, et al. A systematic review of the global magnitude and drivers of violence against sex workers. American Journal of Public Health. 2014; 104(5):e42-e54. [PubMed: 24625169]

Deering K, Lyons T, Feng CX, Nosyk B, Strathdee SA, Montaner JSG, Shannon K. Client demands for unsafe sex: The socioeconomic risk environment for HIV among street and off-street sex workers. Journal of Acquired Immune Deficiency Syndromes. 2013; 63(4):522-531. [PubMed: 23614990]

Dell CA, Roberts G, Kilty J, Taylor K, Daschuk M, Hopkins C, Dell D. Researching prescription drug misuse among First Nations in Canada: starting from a health promotion framework. Substance Abuse: Research and Treatment. 2012; 6:23-31.10.4137/SART.S9247 [PubMed: 22879752]

Dhalla I, Mamdani M, Gomes T, Juurlink D. Clustering of opioid prescribing and opioid-related mortality among family physicians in Ontario. Canadian Family Physician. 2011; 57:e92-e96. [PubMed: 21402956]

Dhalla I, Mamdani M, Sivilotti M, Kopp A, Qureshi O, Juurlink D. Prescribing of opioid analgesics and related mortality before and after the introduction of long-acting oxycodone. CMAJ. 2009; 181(12):891-896.10.1503/cmaj.090784 [PubMed: 19969578]

Doyle S. Canada lags behind United States in drug return, reuse and recycling programs. Canadian Medical Association Journal. 2010; 182(4):E197-E198. [PubMed: 20142378]

Dunkle KL, Jewkes RK, Nduna M, Levin J, Jama N, Khuzwayo N, Duvvury N, et al. Perpetration of partner violence and HIV risk behaviour among young men in the rural Eastern Cape, South Africa. AIDS. 2006; 20(16):2107-2114.10.1097/01.aids.0000247582.00826.52 [PubMed: 17053357]

El-Bassel N, Gilbert L, Wu E, Go H, Hill J. HIV and intimate partner violence among methadonemaintained women in New York City. Social Science \& Medicine. 2005; 61(1):171-183. [PubMed: 15847970]

Firestone M, Fischer B. A qualitative exploration of prescription opioid injection among street-based drug users in Toronto: behaviours, preferences and drug availability. Harm Reduction Journal. 2008; 5(30)10.1186/1477-7517-5-30

Fischer B, Argento E. Prescription opioid related misuse, harms, diversion and interventions in Canada: a review. Pain Physician. 2012; 15(3 Suppl):ES191-203. [PubMed: 22786457]

Fischer B, De Leo J, Allard C, Firestone-Cruz M, Patra J, Rehm J. Exploring Drug Sourcing among Regular Prescription Opioid Users in Canada: Data from Toronto and Victoria. Canadian Journal of Criminology and Criminal Justice. 2009; 51(1):55-72. 
Fischer B, Firestone Cruz M, Rehm J. Illicit opioid use and its key characteristics: a select overview and evidence from a Canadian multisite cohort of illicit opioid users (OPICAN). Canadian Journal of Psychiatry. 2005; 55(10):624-634.

Fischer B, Gooch J, Goldman B, Kurdyak P, Rehm J. Non-medical prescription opioid use, prescription opioid-related harms and public health in Canada: An update 5 years later. Canadian Journal of Public Health. 2014; 105(2):e146-149. [PubMed: 24886852]

Fischer, B.; Rehm, J. Prescription Opioids Misuse, Harms and Control in Canada: A Research and Policy Issues Brief for the Department of Justicer. Vancouver: 2011.

Furlan AD, MacDougall P, Pellerin D, Shaw K, Spitzig D, Wilson G, Wright J. Overview of four prescription monitoring/review programs in Canada. Pain Research \& Management. 2014; 19(2): 102-106. [PubMed: 24716198]

Goldenberg S, Chettiar J, Simo A, Silverman J, Strathdee S, Montaner J, Shannon K, et al. Early sex work initiation independently elevates odds of HIV infection and police arrest among adult sex workers in a Canadian setting. Journal of Acquired Immune Deficiency Syndromes. 2014; 65(1): 122-128. [PubMed: 23982660]

Green TC, Grimes Serrano JM, Licari A, Budman SH, Butler SF. Women who abuse prescription opioids: findings from the Addiction Severity Index-Multimedia Version Connect prescription opioid database. Drug and Alcohol Dependence. 2009; 103(1-2):65-73.10.1016/j.drugalcdep. 2009.03.014 [PubMed: 19409735]

Haydon E, Fischer B, Monga N, Adlaf E. Prescription Drug Abuse in Canada and the Diversion of Prescription Drugs into the Illicit Drug Market. Canadian Journal of Public Health. 2005; 96(6): 459-461. [PubMed: 16350874]

Health Canada. Abuse and Diversion of Controlled Substances - a Guide for Health Professionals. Ottawa, ON: 2006. p. 32Retrieved from http://publications.gc.ca/site/eng/289299/publication.html on July 2, 2014

Health Canada. Statement on the Authorization of Generic OxyContin. Ottawa: 2012. Retrieved from http://www.hc-sc.gc.ca/ahc-asc/media/ftr-ati/_2012/2012_176-eng.php July 2, 2014

Health Canada. Canadian Alcohol and Drug Use Monitoring Survey (CADUMS): Summary Results for 2012. Ottawa, ON: 2013. Retrieved from http://www.hc-sc.gc.ca/hc-ps/drugs-drogues/stat/ _2012/summary-sommaire-eng.phpJuly 2, 2014

Hegarty K, O’Doherty L, Taft A, Chondros P, Brown S, Valpied J, Feder G, et al. Screening and counselling in the primary care setting for women who have experienced intimate partner violence (WEAVE): a cluster randomised controlled trial. The Lancet. 2013; 382(9888):249-258.10.1016/ S0140-6736(13)60052-5

International Narcotics Control Board. Narcotic Drugs Technical Report: Estimated World Requirements for 2013. New York: 2012. Retrieved from http://www.incb.org/incb/en/narcoticdrugs/Technical_Reports/2012/narcotic-drugs-technical-report_2012.html on April 17, 2014

Jewkes RK, Dunkle K, Nduna M, Shai N. Intimate partner violence, relationship power inequity, and incidence of HIV infection in young women in South Africa: a cohort study. Lancet. 2010; 376(9734):41-8.10.1016/S0140-6736(10)60548-X [PubMed: 20557928]

Johnson S, MacDonald SF, Cheverie M, Myrick C, Fischer B. Prevalence and trends of non-medical opioid and other drug use histories among federal correctional inmates in methadone maintenance treatment in Canada. Drug and Alcohol Dependence. 2012; 124(1-2):172-176. [PubMed: 22265193]

Katt M, Chase C, Samokhvalov A, Argento E, Rehm J, Fischer B. Feasibility and Outcomes of a Community-Based Taper-to-Low-Dose-Maintenance Suboxone Treatment Program for Prescription Opioid Dependence in a Remote First Nations Community in Northern Ontario. Journal of Aboriginal Health. 2012; 9(1):52-60.

Katz C, El-Gabalawy R, Keyes K, Martins S, Sareen J. Risk factors for incident nonmedical prescription opioid use and abuse and dependence: Results from a longitudinal nationally representative sample. Drug and Alcohol Dependence. 2013; 132(1-2):107-113. [PubMed: 23399466] 
Kelly L, Dooley J, Cromarty H, Madden S, Hopman W, Minty B, Morgan A. Narcotic-exposed neonates in a First Nations population in northwestern Ontario. Canadian Family Physician. 2011; 57:e441-e447. [PubMed: 22084474]

Kerr T, Stoltz J, Marshall BDL, Lai C, Strathdee SA, Wood E. Childhood Trauma and Injection Drug Use among High-Risk Youth. Journal of Adolescent Health. 2009; 45(3):300-302. Childhood. 10.1016/j.jadohealth.2009.03.007 [PubMed: 19699428]

Krüsi A, Chettiar J, Ridgway A, Abbott J, Strathdee Sa, Shannon K, Strathdee AS, et al. Negotiating safety and sexual risk reduction with clients in unsanctioned safer indoor sex work environments: a qualitative study. American Journal of Public Health. 2012; 102(6):1154-1159.10.2105/AJPH. 2011.300638 [PubMed: 22571708]

Krüsi A, Pacey K, Bird L, Taylor C, Chettiar J, Allan S, Shannon K, et al. Criminalisation of clients: reproducing vulnerabilities for violence and poor health among street-based sex workers in Canada-a qualitative study. BMJ Open. 2014; 4(e005191)10.1136/bmjopen-2014005191

Lankenau SE, Schrager SM, Silva K, Kecojevic A, Bloom JJ, Wong C, Iverson E. Misuse of prescription and illicit drugs among high-risk young adults in Los Angeles and New York. Journal of Public Health Research. 2012; 1(e6):22-30. [PubMed: 22798990]

Lazarus L, Deering K, Nabess R, Gibson K, Tyndall M, Shannon K. Occupational stigma as a primary barrier to health care for street-based sex workers in Canada. Culture, Health \& Sexuality. 2012; 14(2):139-150.

Leclerc, P.; Morissette, C.; Roy, É. Le Volet Montréalais duRéseau SurvUDI Report No 2. Montreal, Quebec: 2010.

Macmillan HL, Wathen CN, Jamieson E, Boyle MH, Shannon HS, Ford-gilboe M, Campbell JC, et al. Screening for intimate partner violence in health care settings: A randomized trial. JAMA. 2009; 302(5):493-501. [PubMed: 19654384]

Manchikanti L, Boswell MV, Hirsch Ja. Lessons learned in the abuse of pain-relief medication: a focus on healthcare costs. Expert Review of Neurotherapeutics. 2013; 13(5):527-544.10.1586/ern.13.33 [PubMed: 23621310]

Martin TL, Woodall KL, McLellan Ba. Fentanyl-related deaths in Ontario, Canada: toxicological findings and circumstances of death in 112 cases (2002-2004). Journal of Analytical Toxicology. 2006; 30(8):603-610. [PubMed: 17132259]

McCabe SE, Cranford JA, Boyd CJ, Teter CJ. Motives, diversion and routes of administration associated with nonmedical use of prescription opioids. Addictive Behaviors. 2007; 32(3):562575. http://dx.doi.org/10.1016/j.addbeh.2006.05.022. [PubMed: 16843611]

Minister of Justice and Attorney General of Canada. House of Commons of Canada, Bill C-36. Ottawa, ON: House of Commons of Canada; 2014. Retrieved from http://www.parl.gc.ca/ HousePublications/Publication.aspx?Language=E\&Mode\&equals; $\&$ DocId\&equals; 6646338\&File\&equals;24\#1 on July 2, 2014

National Advisory Committee on Prescription Drug Misuse. First Do No Harm: Responding to Canada's Prescription Drug Crisis. Ottawa: 2013.

Nosyk B, Marshall B, Fischer B, Montaner J, Wood E, Kerr T. Increases in the availability of prescribed opioids in a Canadian setting. Drug and Alcohol Dependence. 2012; 126(1-2):712.10.1016/j.drugalcdep.2012.03.010 [PubMed: 22480666]

Odinokova V, Rusakova M, Urada LA, Silverman JG, Raj A. Police sexual coercion and its association with risky sex work and substance use behaviors among female sex workers in St. Petersburg and Orenburg, Russia. The International Journal on Drug Policy. 2013; 25(1): 96.10.1016/j.drugpo.2013.06.008 [PubMed: 23916802]

Ontario Ministry of Health and Long-Term Care. Expert Working Group on Narcotic Addiction Report: The Way Forward: Stewardship for Prescription Narcotics in Ontario. Toronto, ON: 2012. Retrieved from http://www.health.gov.on.ca/en/public/programs/mentalhealth/narc_report.aspx on July 2, 2014

Pergolizzi JV, Gharibo C, Passik S, Labhsetwar S, Taylor R, Pergolizzi JS, Müller-Schwefe G. Dynamic risk factors in the misuse of opioid analgesics. Journal of Psychosomatic Research. 2012; 72(6):443-451.10.1016/j.jpsychores.2012.02.009 [PubMed: 22656441] 
Popova S, Patra J, Mohapatra S, Fischer B, Rehm J. How many people in Canada use prescription opioids non-medically in general and street drug using populations? Canadian Journal of Public Health. 2009; 100(2):104-108. [PubMed: 19839284]

Ramachandran D, Covarrubias L, Watson C, Decker M. How you screen is as important as whether you screen: a qualitative analysis of violence screening practices in reproductive health clinics. Journal of Community Health. 2013; 38(5):856-863.10.1007/s10900-013-9690-0 [PubMed: 23645349]

Rhodes T, Simic M, Baros S, Platt L, Zikic B. Police violence and sexual risk among female and transvestite sex workers in Serbia: qualitative study. BMJ. 2008; 337(7669):560-563.

Rio Navarro J, Cohen J, Rocillo Arechaga E, Zuniga E, Act MSFE. Physical and sexual violence, mental health indicators, and treatment seeking among street-based population groups in Tegucigalpa, Honduras. Pan American Journal of Public Health. 2012; 31(5,SI):388-395. [PubMed: 22767039]

Shannon K, Bright V, Allinott S, Alexson D, Gibson K, Tyndall MW. Community-based HIV prevention research among substance-using women in survival sex work: the Maka Project Partnership. Harm Reduction Journal. 2007; 4(20)10.1186/1477-7517-4-20

Shannon K, Csete J. Violence, Condom Negotiation, and HIV/STI Risk Among Sex Workers. JAMA. 2010; 304(5):573-574. [PubMed: 20682941]

Shannon K, Kerr T, Allinott S, Chettiar J, Shoveller J, Tyndall MW. Social and structural violence and power relations in mitigating HIV risk of drug-using women in survival sex work. Social Science \& Medicine. 2008; 66(4):911-921.10.1016/j.socscimed.2007.11.008 [PubMed: 18155336]

Shannon K, Kerr T, Strathdee S, Shoveller J, Montaner J, Tyndall M. Prevalence and structural correlates of gender based violence among a prospective cohort of female sex workers. BMJ. 2009; 339(b2939)10.1136/bmj.b2939

Shannon K, Leiter K, Phaladze N, Hlanze Z, Tsai AC, Heisler M, Weiser SD, et al. Gender inequity norms are associated with increased male-perpetrated rape and sexual risks for HIV infection in Botswana and Swaziland. PLoS One. 2012; 7(1):e28739.10.1371/journal.pone.0028739 [PubMed: 22247761]

Sherman S, Smith L, Laney G, Strathdee S. Social influences on the transition to injection drug use among young heroin sniffers: a qualitative analysis. International Journal of Drug Policy. 2002; 13(2):113-120. http://dx.doi.org/10.1016/S0955-3959(02)00010-5.

Shield KD, Ialomiteanu A, Fischer B, Rehm J. Assessing the prevalence of non-medical prescription opioid use in the Canadian general adult population: evidence of large variation depending on survey questions used. BMC Psychiatry. 2013; 13(6)10.1186/1471-244X-13-6

Small W, Kerr T, Charette J, Schechter MT, Spittal PM. Impacts of intensified police activity on injection drug users: Evidence from an ethnographic investigation. International Journal of Drug Policy. 2006; 17(2):85-95. http://dx.doi.org/10.1016/j.drugpo.2005.12.005.

Sproule B, Li S. Changing patterns in opioid addiction: Characterizing users of oxycodone and other opioids. Canadian Family Physician. 2009; 55(1):68-69. [PubMed: 19155373]

Stene LE, Dyb G, Tverdal A, Jacobsen GW, Schei B. Intimate partner violence and prescription of potentially addictive drugs: prospective cohort study of women in the Oslo Health Study. BMJ Open. 2012; 2(2):e000614.10.1136/bmjopen-2011-000614

Stockman JK, Lucea MB, Campbell JC. Forced sexual initiation, sexual intimate partner violence and HIV risk in women: a global review of the literature. AIDS and Behavior. 2013; 17(3):832847.10.1007/s10461-012-0361-4 [PubMed: 23143750]

Stolz J-A, Shannon K, Kerr T, Zhang R, Montaner J, Wood E. Associations between childhood maltreatment and sex work in a cohort of drug-using youth. Social Science \& Medicine. 2007; 65(6):1214-1221. [PubMed: 17576029]

Strathdee SA, Patrick D, Archibald C, Ofner M, Cornelisse P, Rekart M, O'Shaughnessy M. Social determinants predict needle-sharing behaviour among injection drug users in Vancouver, Canada. Addiction. 1997; 92(10):1339-1347. [PubMed: 9489050]

Stueve A, Duran R, Doval AS, Blome J. Time-space sampling in minority communities: results with young Latino men who have sex with men. American Journal of Public Health. 2001; 91(6):922926. [PubMed: 11392935] 
Substance Abuse and Mental Health Service Administration. Highlights of the 2009 Drug Abuse Warning Network (DAWN) Findings on Drug-Related Emergency Department Visits. Rockville: 2010. Retrieved from http://oas.samhsa.gov/2k10/dawn034/edhighlights.htm on June 30, 2014

Supreme Court of Canada. Canada (Attorney General) vs Bedford Ottawa SCC 72. Ottawa, ON: 2013. (p. 3 S.C.R. 1101) Retrieved from http://scc-csc.lexum.com/scc-csc/scc-csc/en/item/13389/ index.do on July 2, 2014

Surratt H, Inciardi J, Kurtz S. Prescription opioid abuse among drug-involved street-based sex workers. Journal of Opioid Management. 2006; 2(5):283-289. [PubMed: 17319260]

Surratt H, Kurtz SP, Cicero TJ. Alternate routes of administration and risk for HIV among prescription opioid abusers. Journal of Addictive Diseases. 2011; 30(4):334341.10.1080/10550887.2011.609805 [PubMed: 22026525]

Tetrault JM, Desai Ra, Becker WC, Fiellin Da, Concato J, Sullivan LE. Gender and non-medical use of prescription opioids: results from a national US survey. Addiction. 2008; 103(2):258268.10.1111/j.1360-0443.2007.02056.x [PubMed: 18042194]

Ulibarri MD, Strathdee Sa, Lozada R, Magis-Rodriguez C, Amaro H, O’Campo P, Patterson TL. Intimate partner violence among female sex workers in two Mexico-U.S. border cities: partner characteristics and HIV risk-behaviors as correlates of abuse. Psychological Trauma Theory Research Practice and Policy. 2010; 2(4):318-325.10.1037/a0017500

Volkow N, McLellan T. Curtailing diversion and abuse of opioid analgesics without Jeopardizing pain treatment. JAMA. 2011; 305:1346-1347.10.1001/jama.2011.369 [PubMed: 21467287]

Werb D, Wood E, Small W, Strathdee S, Li K, Montaner J, Kerr T. Effects of police confiscation of illicit drugs and syringes among injection drug users in Vancouver. International Journal of Drug Policy. 2008; 19(4):332-338. http://dx.doi.org/10.1016/j.drugpo.2007.08.004. [PubMed: 17900888]

Whiteside LK, Walton Ma, Bohnert ASB, Blow FC, Bonar EE, Ehrlich P, Cunningham R. Nonmedical prescription opioid and sedative use among adolescents in the emergency department. Pediatrics. 2013; 132(5):825-832.10.1542/peds.2013-0721 [PubMed: 24167166]

Wu L, Woody GE, Yang C, Blazer DG. Subtypes of nonmedical opioid users: results from the National Epidemiologic Survey on Alcohol and Related Conditions. Drug and Alcohol Dependence. 2011; 112(1-2):69-80. Subtypes. 10.1016/j.drugalcdep.2010.05.013 [PubMed: 20580168]

Young AM, Havens JR, Leukefeld CG. Route of administration for illicit prescription opioids: a comparison of rural and urban drug users. Harm Reduction Journal. 2010;

7(24)10.1186/1477-7517-7-24 


\section{Highlights}

- Nearly one-fifth of sex workers report nonmedical prescription opioid use (NPOU).

- Partner violence and police harassment were independently correlated with recent NPOU.

- Further prevention/management strategies tailored to this population are needed.

- This is the first study to longitudinally examine NPOU among sex workers in Canada. 


\section{TABLE 1}

Individual and socio-structural characteristics of sex workers in Metro Vancouver who used prescription opioids (POs) in the last six months compared to those who did not, at baseline

\begin{tabular}{|c|c|c|c|c|}
\hline \multirow{2}{*}{ Characteristic } & \multirow{2}{*}{ Total $(\%)(N=692)$} & \multicolumn{2}{|c|}{ Recent PO use } & \multirow{2}{*}{$p$ - value } \\
\hline & & Yes $(\%)(n=130)$ & No $(\%)(n=562)$ & \\
\hline \multicolumn{5}{|l|}{ Individual \& Historical Variables } \\
\hline Age (med, IQR) & $34(28-42)$ & $35(28-41)$ & $34(28-42)$ & 0.960 \\
\hline Canadian-born & $508(73.4)$ & $126(96.9)$ & $382(68.0)$ & $<0.001$ \\
\hline Aboriginal ancestry & $251(36.3)$ & $57(43.9)$ & $194(34.5)$ & 0.048 \\
\hline HIV seropositivity & $78(11.3)$ & $22(16.9)$ & $56(10.0)$ & 0.031 \\
\hline STI seropositivity & $77(11.1)$ & $14(10.8)$ & $63(11.2)$ & 0.885 \\
\hline Education, high school or greater & $361(52.2)$ & $64(49.2)$ & 297 (52.9) & 0.457 \\
\hline Sexual minority & $177(25.6)$ & $49(37.7)$ & $128(22.8)$ & $<0.001$ \\
\hline Injection drug use ${ }^{\dagger}$ & $277(40.0)$ & $102(78.5)$ & $175(31.1)$ & $<0.001$ \\
\hline Non-injection drug use ${ }^{\dagger}$ & $480(69.4)$ & $129(99.2)$ & $351(62.5)$ & $<0.001$ \\
\hline Childhood abuse & $493(71.2))$ & $113(86.9)$ & $380(67.6)$ & $<0.001$ \\
\hline \multicolumn{5}{|l|}{ Social \& Structural Variables } \\
\hline Exchanged sex while high ${ }^{\dagger}$ & $425(61.4)$ & $117(90.0)$ & $308(54.8)$ & $<0.001$ \\
\hline Exchanged sex for drugs ${ }^{\dagger}$ & $208(30.1)$ & $66(50.8)$ & $142(25.3)$ & $<0.001$ \\
\hline \multicolumn{5}{|l|}{ Physical or Sexual Violence } \\
\hline By client ${ }^{\dagger}$ & $162(23.4)$ & $47(36.2)$ & $115(20.5)$ & $<0.001$ \\
\hline By intimate partner ${ }^{\dagger}$ & $147(21.2)$ & $48(36.9)$ & $99(17.6)$ & $<0.001$ \\
\hline \multicolumn{5}{|l|}{ Police Harassment } \\
\hline Without arrests ${ }^{\dagger}$ & $266(38.4)$ & $74(56.9)$ & $192(34.2)$ & $<0.001$ \\
\hline Including arrests ${ }^{\dagger}$ & $277(40.0)$ & $78(60.0)$ & $199(35.4)$ & $<0.001$ \\
\hline \multicolumn{5}{|l|}{ Primary place to solicit clients } \\
\hline Street/public ${ }^{\dagger}$ & $382(55.2)$ & $102(78.5)$ & $280(49.8)$ & REF \\
\hline Indoor establishment ${ }^{\dagger}$ & $196(28.3)$ & $8(6.5)$ & $188(33.5)$ & $<0.001$ \\
\hline Independent ${ }^{\dagger}$ & $114(16.5)$ & $20(15.4)$ & $94(16.7)$ & $<0.001$ \\
\hline \multicolumn{5}{|l|}{ Intimate Partner-level Data } \\
\hline Inconsistent condom use ${ }^{\dagger}$ & $268(38.7)$ & $55(42.3)$ & $213(37.9)$ & 0.354 \\
\hline Sourced drugs from partner ${ }^{\dagger}$ & $140(20.2)$ & $42(32.3)$ & $98(17.4)$ & $<0.001$ \\
\hline Partner used non-injection drugs ${ }^{\dagger}$ & $242(35.0)$ & $63(48.5)$ & $179(31.9)$ & $<0.001$ \\
\hline Partner used injection drugs ${ }^{\dagger}$ & $69(10.0)$ & $22(16.9)$ & $47(8.36)$ & 0.006 \\
\hline
\end{tabular}

${ }^{\dagger}$ Last six months 
TABLE 2

Longitudinal bivariate and multivariate GEE correlates of recent prescription opioid (PO) use among sex workers in Metro Vancouver, AESHA Cohort 2010-2013

\begin{tabular}{|c|c|c|}
\hline \multirow{2}{*}{ Characteristic } & \multicolumn{2}{|c|}{ Odds Ratio (OR) } \\
\hline & Unadjusted OR (95\% CI) & Adjusted OR (95\% CI) \\
\hline \multicolumn{3}{|l|}{ Individual \& Historical Variables } \\
\hline Age & $1.00(0.98-1.01)$ & - \\
\hline Canadian-born & $9.31(4.14-20.98)^{*}$ & \\
\hline Education, high school or greater & $0.83(0.61-1.13)$ & - \\
\hline Aboriginal ancestry & $1.23(0.90-1.68)$ & - \\
\hline Sexual minority & $1.65(1.19-2.28)^{*}$ & \\
\hline HIV seropositivity & $1.18(0.79-1.77)$ & - \\
\hline STI seropositivity & $1.08(0.72-1.63)$ & - \\
\hline Childhood abuse & $2.94(1.91-4.52)^{*}$ & \\
\hline \multicolumn{3}{|l|}{ Social \& Structural Variables } \\
\hline Exchanged sex while high ${ }^{\dagger}$ & $3.74(2.76-5.06)^{*}$ & $3.26(2.29-4.64)^{*}$ \\
\hline Exchanged sex for drugs ${ }^{\dagger}$ & $2.56(1.97-3.32)^{*}$ & \\
\hline Police harassment or arrest ${ }^{\dagger}$ & $2.38(1.89-3.01)^{*}$ & $1.83(1.43-2.35)^{*}$ \\
\hline \multicolumn{3}{|l|}{ Physical or Sexual Violence } \\
\hline By client ${ }^{\dagger}$ & $1.82(1.41-2.35)^{*}$ & \\
\hline By intimate partner ${ }^{\dagger}$ & $2.12(1.57-2.86)^{*}$ & $1.65(1.21-2.24)^{*}$ \\
\hline \multicolumn{3}{|l|}{ Intimate Partner-level Data } \\
\hline Partner used non-injection drugs ${ }^{\dagger}$ & $1.76(1.36-2.28)^{*}$ & \\
\hline Partner used injection drugs ${ }^{\dagger}$ & $2.27(1.55-3.31)^{*}$ & $1.66(1.11-2.49)^{* *}$ \\
\hline Sourced drugs from intimate partner ${ }^{\dagger}$ & $1.66(1.21-2.28)^{*}$ & \\
\hline Inconsistent condom use with partner ${ }^{\dagger}$ & $1.15(0.87-1.51)$ & - \\
\hline \multicolumn{3}{|l|}{ Primary place to solicit clients } \\
\hline Indoors (vs. street/public) $)^{\dagger}$ & $0.26(0.15-0.44)^{*}$ & \\
\hline Independent (vs. street/public) $)^{\dagger}$ & $0.77(0.59-1.02)$ & - \\
\hline \multicolumn{3}{|l|}{${ }^{*} p<0.01$} \\
\hline \multicolumn{3}{|l|}{$\begin{array}{l}* * \\
\quad p<0.05\end{array}$} \\
\hline Last six months & & \\
\hline
\end{tabular}

